\title{
VELOCITIES OF MANTLE LOVE AND RAYLEIGH WAVES OVER MULTIPLE PATHS
}

\author{
By M. Nafi Torsöz and Art Ben-Menahem
}

\begin{abstract}
Phase velocities of Love waves from five major earthquakes are measured over six great circle paths in the period range of 50 to 400 seconds. For two of the great circle paths the phase velocities of Rayleigh waves are also obtained. The digitized seismograph traces are Fourier analyzed, and the phase spectra are used in determining the phase velocities. Where the great circle paths are close, the phase velocities over these paths are found to be in very good agreement with each other indicating that the measured velocities are accurate and reliable. Phase velocities of Love waves over paths that lie far from each other are different, and this difference is consistent and much greater than the experimental error. From this it is concluded that there are lateral variations in the structure of the earth's mantle. One interpretation of this variation is that the mantle under the continents is different from that under the oceans, since the path with the highest phase velocities is almost completely oceanic. This interpretation, however, is not unique and variations under the oceans and continents are also possible.

Group velocities are computed from the phase velocities and are also directly measured from the seismograms. The group-velocity curve of Love waves has a plateau between periods of 100 and 300 seconds with a shallow minimum at about 290 seconds. The sources of error in both Fourier analysis and direct time domain methods of phase velocity measurement are discussed.
\end{abstract}

\section{INTRODUCTION}

The dispersive properties of surface waves are being used extensively in studying the structure of the earth's crust and mantle. The accuracy by which the structure can be determined is limited by the accuracy of the observed values of the phase and group velocities. At relatively short periods (less than 60-70 seconds), the local effects on the waves are such that only regional, rather than universal, dispersion curves are justified. At very long periods, free oscillation data have accurately fixed the phase velocity curves for both Love and Rayleigh waves. For the intermediate periods, there have been many measurements of phase and group velocities of Love and Rayleigh waves (Satô, 1958; Nafe and Brune, 1960; Brune, Ewing and Kuo, 1961; Brune, Benioff and Ewing, 1961; Ben-Menahem and Toksöz, 1962; Båth and Arroyo, 1962; Matumoto and Satô, 1962). Most of the observational data, however, show some scatter, and various measurements differ by as much as, and occasionally more than, one per cent of the measured value (Kovach and Anderson, 1962). Part of this variation may be due to the path differences and lateral variations in the structure. Before this question and the question of the best model for the earth's mantle can be resolved, it is essential that more precise and consistent surface wave dispersion data is obtained.

As a first step in this direction, we have measured phase velocities of Love waves, over complete great circle paths, from five major earthquakes: New Guinea (February 1, 1938), Assam (August 15, 1950), Kamchatka (November 4, 1952), Mongolia (December 4, 1957), and Alaska (July 10, 1958). For two of these, Assam and Mongolia, phase velocities of Rayleigh waves are also determined. The epi- 
center, origin time, and other pertinent information regarding these earthquakes are given in table 1. The great circle paths are through Pasadena, California with one exception: Wilkes, Antarctica is used in addition to Pasadena for the Alaska earthquake. Figure 1 shows the great circle paths through Pasadena and Wilkes.

TABLE 1

List of Earthquakes and Coordinates of the Recording Stations

\begin{tabular}{|c|c|c|c|c|}
\hline \multirow{2}{*}{ Name } & \multirow{2}{*}{ Date } & \multirow{2}{*}{ Origin Time } & \multicolumn{2}{|c|}{ Epicenter } \\
\hline & & & Latitude & Longitude \\
\hline New Guinea & Feb. 1, 1938 & $19: 04: 21$ & $05^{\circ} 00^{\prime} \mathrm{S}$ & $131^{\circ} 30^{\prime} \mathrm{E}$ \\
\hline Assam & Aug. 15, 1950 & $14: 09: 29$ & $28^{\circ} 24^{\prime} \mathrm{N}$ & $096^{\circ} 42^{\prime} \mathrm{E}$ \\
\hline Kamchatka & Nov. 4,1952 & $16: 58: 20$ & $52^{\circ} 42^{\prime} \mathrm{N}$ & $160^{\circ} 18^{\prime} \mathrm{E}$ \\
\hline Mongolia & Dec. 4,1957 & $03: 37: 45$ & $45^{\circ} 15^{\prime} \mathrm{N}$ & $099^{\circ} 24^{\prime} \mathrm{E}$ \\
\hline Alaska & July 10,1958 & $06: 15: 54$ & $58^{\circ} 18^{\prime} \mathrm{N}$ & $136^{\circ} 54^{\prime} \mathrm{W}$ \\
\hline Stations & \multicolumn{2}{|c|}{$\begin{array}{l}\text { Pasadena, California } \\
\text { Wilkes, Antarctica }\end{array}$} & $\begin{array}{l}34^{\circ} 08^{\prime} 54^{\prime \prime} \mathrm{N} \\
66^{\circ} 35^{\prime} \mathrm{S}\end{array}$ & $\begin{array}{l}118^{\circ} 10^{\prime} 18^{\prime \prime} \mathrm{W} \\
110^{\circ} 35^{\prime} \mathrm{E}\end{array}$ \\
\hline
\end{tabular}

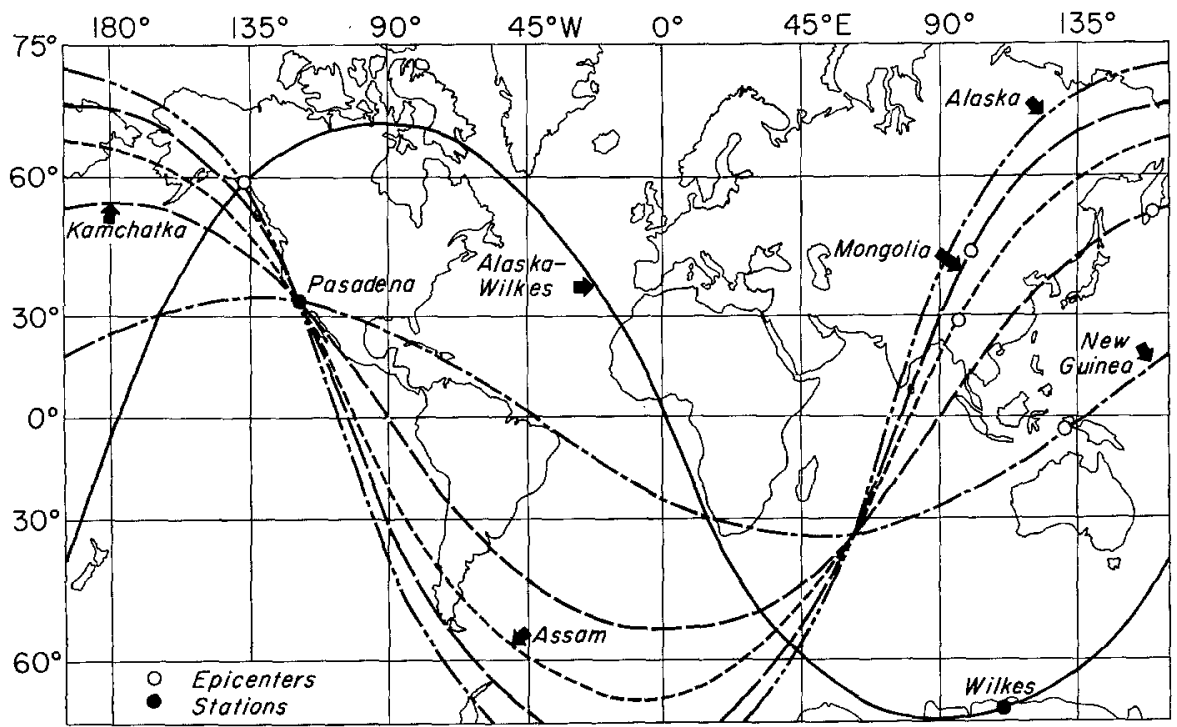

Fig. 1. Great circle paths.

With the exception of New Guinea, and Alaska-Wilkes, all paths are fairly close to one another, and one would expect the measured phase velocities to be approximately the same regardless of the lateral variation in mantle structure.

In all cases, the phase velocities were determined by the Fourier analysis method where the difference between the phase spectra of two successive passages of an odd or even order wave is used to determine the time delay for each phase. This method has become well-known since it was introduced by Valle (1949) and used 
by Sato (1958). In this paper a brief description of the method is given prior to its application to individual cases. The phase velocities from each one of the five earthquakes are then determined, and the group velocities are derived from the phase velocities. The second half of the paper is devoted to a comparison of the Fourier analysis method of phase velocity determination with direct measurement from the record. The sources of error in the Fourier analysis method are described and an approximate error bound is given.

\section{Phase Velocity Determination Using Fourier Phase Spectra}

In this method, Fourier phase spectra are used for determining the phase delay of a given frequency between two stations. Let us take two recording stations over the same great circle path, with distances $\Delta_{1}$ and $\Delta_{2}$ from the epicenter. Assume that a Love or Rayleigh wave train is recorded at both stations. The desired wave train can be digitized and Fourier analyzed. Let $t_{1}$ and $t_{2}$ be the travel time from the source to the beginning of each Fourier window and $\phi_{1}(\omega)$ and $\phi_{2}(\omega)$ be the corresponding Fourier phase spectra. Then, the phase velocity $C$ is given by

$$
C(T)=\frac{\Delta_{2}-\Delta_{1}}{t_{2}-t_{1}+T\left[\left(\phi_{2}-\phi_{1}\right)+N\right]}
$$

where $T$ is the period and $N$ is an integer. The need for $N$ arises from the fact that the trigonometric functions are multi-valued, and one cannot determine uniquely the initial integer of $\phi_{2}$ relative to $\phi_{1}$. Once $N$ is fixed, it remains unchanged over the whole spectrum. The changes in phase will normally exceed one circle, and every time $\phi$ goes through zero it is incremented by one circle.

When the phase velocities are determined from a single station, two successive passages of the same wave in the same direction such as $G_{1}$ and $G_{3}, G_{2}-G_{4}$, or $R_{3}-R_{5}$ are used for determining the phase velocity. In this case formula (1) becomes

$$
C(T)=\frac{\Delta_{0}}{\delta t+T\left(\delta \phi+N+\frac{1}{2}\right)}
$$

where $\Delta_{0}=$ length of great circle, $\delta t=t_{n+2}-t_{n}, \delta \phi=\phi_{n+2}-\phi_{n}$, and the $+\frac{1}{2}$ circle phase shift is due to two extra polar passages, with a $\pi / 2$ phase shift per polar passage (Brune, Nafe, and Alsop, 1961).

The use of pairs of odd or even order surface waves, rather than odd-even combinations, in velocity measurement, is necessary to avoid the possibility of introducing an error due to the unknown character of the source. The source may contribute in a different way to waves leaving it in opposite directions. An error of this kind arises, for example, from the finiteness of source (Ben-Menahem, 1961). The differential phase between displacements of two opposite-going surface waves is given by:

$$
D_{\phi}=\frac{\phi_{n+1}-\phi_{n}}{2 \pi}=\frac{f}{C}\left(\Delta_{0}-2 \Delta_{1}+b \cos \theta_{0}\right)+M+\frac{1}{4} \quad n=1,3,5 \cdots
$$


and a similar formula for even values of $n . \Delta_{1}$ is the distance from the source to the station, $b=$ fault length, $\theta_{0}=$ angle between the fault trace and the great circle path. The term involving $b \cos \theta_{0}$ is due to the finiteness of the source, and a fault of $100 \mathrm{~km}$ can perturb the phase as much as 0.2 circles at the period of 100 seconds. This is a considerable error in the phase, and it cannot be neglected.

\section{Phase Velocities}

Phase velocities are determined for six great circle paths for Love waves; for two of these paths we also have the phase velocities of Rayleigh waves. The pertinent

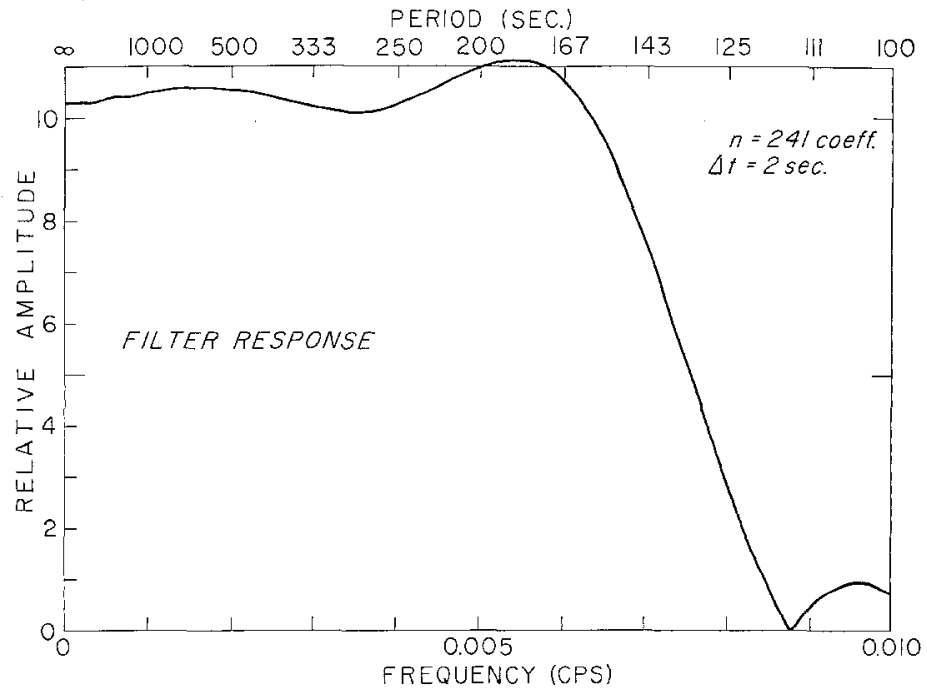

FIG. 2. Typical low-pass digital filter response.

waves were digitized with the sampling interval of two seconds (Mongolia $G$ waves at 1 second intervals) and the digital data were then processed on an IBM 7090 computer where it was detrended, filtered, and plotted. In the case of Love waves it is difficult to determine the beginning and the end of the pulse by inspecting the unfiltered seismogram. Filtering process clears the wave form of excessive interference and facilitates choosing the window. In the case of Rayleigh waves a group velocity window can be used in determining the onset and the end of the pulse. The filtering consists of low-pass filtering with a cut-off frequency so chosen as to minimize interference and noise and also to reject the frequency bands that do not have sufficient power in both pulses. A typical filter response is shown in figure 2. Table 2 lists the onset and end times of the filtered pulses used in the analyses, the cutoff frequency of the low-pass filter used, epicentral distance to station, and the length of the great circle for each earthquake. The filtered pulses were Fourier analyzed and the phases were then used in equation 2 to compute the phase velocities. 


\section{Rayleigh Waves}

(a) Mongolia Earthquake. The phase velocities of Rayleigh waves were computed and published earlier (Ben-Menahem and Toksöz, 1962). These same values are listed in table 3 after slight correction for the length of the great circle path.

(b) Assam Earthquake. The phase velocities are computed from $R_{3}$ and $R_{5}$, for great circle path through Pasadena. The amplitude and phase spectra are shown in figure 3 and the phase velocities are tabulated in table 3 . The original traces were exhibited by Ewing and Press (1954).

TABLE 2

List of Phases, Filter Characteristics, and Epicentral Distances

\begin{tabular}{|c|c|c|c|c|c|c|c|}
\hline \multirow{2}{*}{ Earthquake } & \multirow{2}{*}{ Station } & \multirow{2}{*}{ Phase } & \multicolumn{2}{|c|}{ Time of the Pulse } & \multirow{2}{*}{$\begin{array}{l}\text { Filter } \\
\text { Cut-off } \\
\text { Period } \\
\text { (second) }\end{array}$} & \multirow{2}{*}{$\begin{array}{c}\text { Epicentral } \\
\text { Distance }\end{array}$} & \multirow{2}{*}{$\begin{array}{c}\text { Length of } \\
\text { Great Circle } \\
\text { Path }\end{array}$} \\
\hline & & & Onset & End & & & \\
\hline \multirow[t]{4}{*}{ New Guinea } & Pasadena & $\mathrm{G}_{1}$ & $19: 47: 40$ & $19: 51: 40$ & 55 & \multirow{4}{*}{12194} & \multirow{4}{*}{40054} \\
\hline & Pasadena & $\mathrm{G}_{2}$ & $20: 48: 04$ & $20: 53: 02$ & 55 & & \\
\hline & Pasadena & $\mathrm{G}_{3}$ & $22: 17: 52$ & $22: 24: 40$ & 55 & & \\
\hline & Pasadena & $\mathrm{G}_{4}$ & $23: 16: 40$ & $23: 23: 48$ & 55 & & \\
\hline \multirow[t]{4}{*}{ Assam } & Pasadena & $\mathrm{R}_{3}$ & $17: 42: 53$ & $18: 19: 53$ & 90 & \multirow{4}{*}{12174} & \multirow{4}{*}{40022} \\
\hline & Pasadena & $\mathrm{R}_{5}$ & $20: 23: 53$ & $21: 30: 51$ & 90 & & \\
\hline & Pasadena & $\mathrm{G}_{1}$ & $14: 57: 23$ & $15: 01: 23$ & 67 & & \\
\hline & Pasadena & $\mathrm{G}_{3}$ & $17: 27: 47$ & $17: 36: 33$ & 67 & & \\
\hline \multirow[t]{2}{*}{ Kamchatka } & Pasadena & $\mathrm{G}_{2}$ & $19: 05: 06$ & $19: 10: 26$ & 100 & \multirow{2}{*}{6539} & \multirow{2}{*}{40032} \\
\hline & Pasadena & $\mathrm{G}_{4}$ & $21: 35: 06$ & $21: 46: 00$ & 100 & & \\
\hline \multirow[t]{2}{*}{ Mongolia } & Pasadena & $\mathrm{G}_{1}$ & $04: 16: 15$ & $04: 21: 50$ & 80 & \multirow{2}{*}{10434} & \multirow{2}{*}{40019} \\
\hline & Pasadena & $\mathrm{G}_{3}$ & $06: 46: 15$ & $06: 55: 45$ & 80 & & \\
\hline \multirow[t]{2}{*}{ Alaska } & Pasadena & $\mathrm{G}_{2}$ & $08: 31: 16$ & $08: 42: 26$ & 125 & \multirow{2}{*}{3025} & \multirow{2}{*}{40016} \\
\hline & Pasadena & $\mathrm{G}_{4}$ & $10: 59: 52$ & $11: 15: 18$ & 125 & & \\
\hline \multirow[t]{2}{*}{ Alaska } & Wilkes & $\mathrm{G}_{2}$ & $07: 38: 00$ & $07: 48: 12$ & 125 & \multirow{2}{*}{16583} & \multirow{2}{*}{40018} \\
\hline & Wilkes & $\mathrm{C}_{4}$ & $10: 04: 52$ & $10: 20: 50$ & 125 & & \\
\hline
\end{tabular}

\section{Love Waves}

(a) Mongolia Earthquake. The unfiltered Pasadena strain seismogram showing $G_{1}$ and $G_{3}$ are given in figure 4 , and the spectra are given in figure 5. Phase velocities are listed in table 4.

(b) Assam Earthquake. The Pasadena E-W strain recordings of $G_{1}$ and $G_{3}$ are used for phase velocity measurement. Seismogram traces are shown in figure 6 , and the spectra in figure 7 .

(c) Alaska Earthquake. The $G_{2}$ and $G_{4}$ phases recorded by E-W component on the Press-Ewing seismograph system were used in determining the phase velocities over a great circle path through Pasadena. The re-traced unfiltered and filtered 
TABLE 3

Phase Velocitetes of Rayleigh Waves

\begin{tabular}{|c|c|c|c|}
\hline \multirow{2}{*}{ Frequency (cps) } & \multirow{2}{*}{ Period (sec.) } & \multicolumn{2}{|c|}{ Phase Velocity $(\mathrm{km} / \mathrm{sec})$} \\
\hline & & Mongolia, $R_{6}-R_{3}$ & Assam, $R_{5}-R_{3}$ \\
\hline .0028 & 357.14 & 5.627 & - \\
\hline .0029 & 344.83 & 5.554 & - \\
\hline .0030 & 333.33 & 5.485 & 5.509 \\
\hline .0031 & 322.58 & 5.415 & 5.428 \\
\hline .0032 & 312.50 & 5.358 & 5.364 \\
\hline .0033 & 303.03 & 5.301 & 5.312 \\
\hline .0034 & 294.12 & 5.229 & 5.244 \\
\hline .0035 & 285.71 & 5.171 & 5.179 \\
\hline .0036 & 277.78 & 5.118 & 5.121 \\
\hline .0037 & 270.27 & 5.060 & 5.067 \\
\hline .0038 & 263.16 & 5.003 & 5.004 \\
\hline .0039 & 256.41 & 4.957 & 4.957 \\
\hline .0040 & 250.00 & 4.913 & 4.919 \\
\hline .0041 & 243.90 & 4.862 & 4.867 \\
\hline .0042 & 238.09 & 4.817 & 4.818 \\
\hline .0043 & 232.56 & 4.781 & 4.780 \\
\hline .0044 & 227.27 & 4.744 & 4.743 \\
\hline .0045 & 222.22 & 4.710 & 4.713 \\
\hline .0046 & 217.39 & 4.682 & 4.680 \\
\hline .0047 & 212.77 & 4.651 & 4.648 \\
\hline .0048 & 208.33 & 4.612 & 4.613 \\
\hline .0049 & 204.08 & 4.588 & 4.595 \\
\hline .0050 & 200.00 & 4.568 & 4.566 \\
\hline .0052 & 192.31 & 4.523 & 4.524 \\
\hline .0054 & 185.19 & 4.479 & 4.483 \\
\hline .0056 & 178.57 & 4.434 & 4.436 \\
\hline .0058 & 172.41 & 4.398 & 4.403 \\
\hline .0060 & 166.67 & 4.370 & 4.381 \\
\hline .0062 & 161.29 & 4.349 & 4.339 \\
\hline .0064 & 156.25 & 4.316 & 4.319 \\
\hline .0066 & 151.52 & 4.288 & 4.291 \\
\hline .0068 & 147.06 & 4.279 & 4.271 \\
\hline .0070 & 142.86 & 4.268 & 4.253 \\
\hline .0072 & 138.89 & 4.255 & 4.243 \\
\hline .0074 & 135.14 & 4.247 & 4.232 \\
\hline .0076 & 131.58 & 4.234 & - \\
\hline .0078 & 128.21 & 4.217 & 4.227 \\
\hline .0080 & 125.00 & 4.203 & 4.224 \\
\hline
\end{tabular}

pulses are shown in figure 8 . The spectra are shown in figure 9 . Phase velocities were also computed from $G_{2}-G_{4}$ combination of the recordings at Wilkes. The original seismogram and the filtered traces are shown in figure 10 . The spectra are given in figure 11. Although the recordings were excellent at this station, the drum speed was not uniform causing the results to be somewhat unreliable.

(d) Kamchatka Earthquake. $G_{2}$ and $G_{4}$ phases from the Pasadena recordings of this earthquake were used for the determination of the phase velocity. The original 


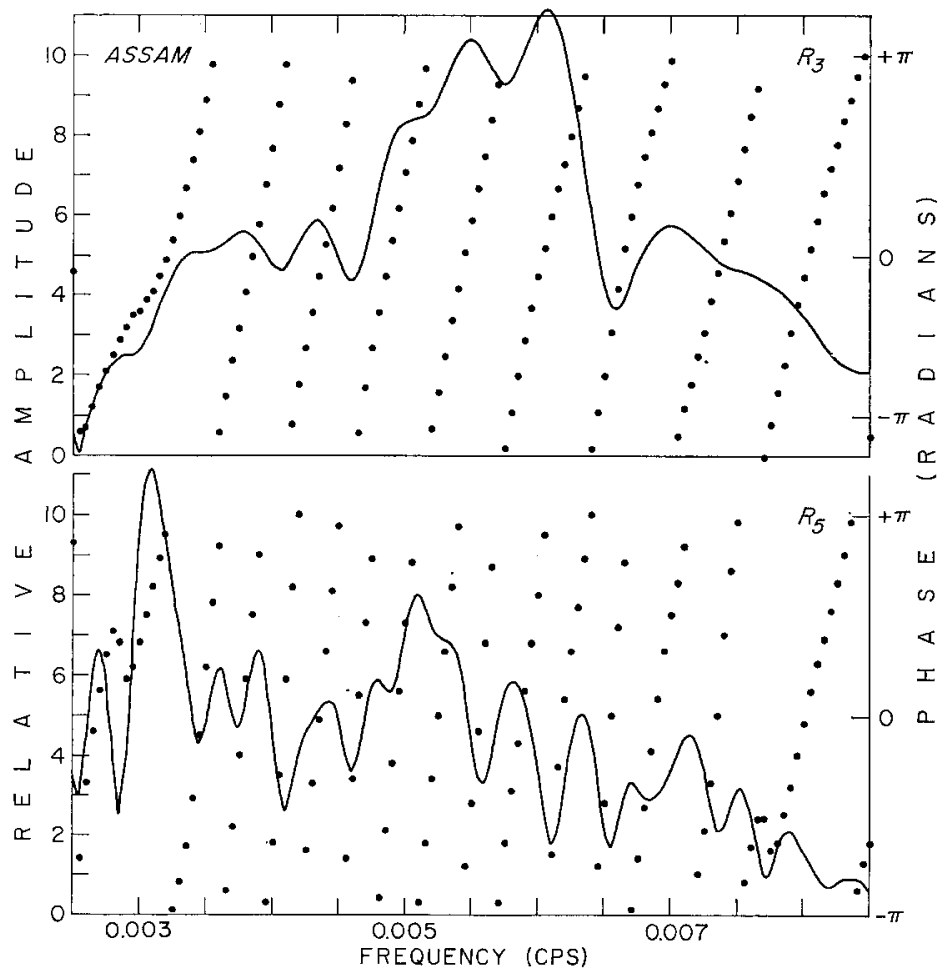

FIa. 3. Amplitude and phase spectra of $\mathbf{R}_{3}$ and $\mathbf{R}_{5}$ of the Assam earthquake

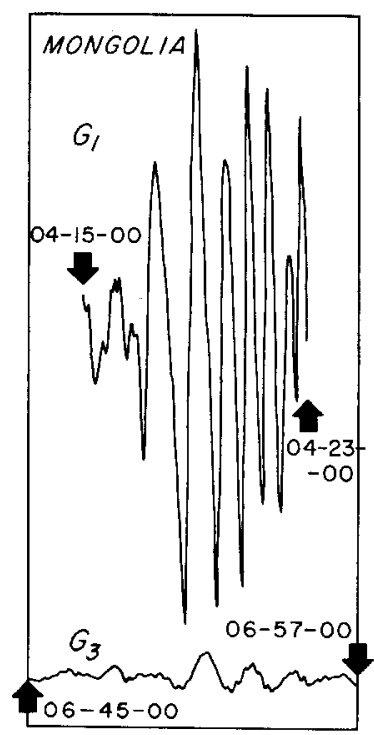

FIG. 4. $\mathrm{G}_{1}$ and $\mathrm{G}_{3}$ traces from the Mongolia earthquake recorded by Pasadena E-W strain seismograph. 
seismogram was exhibited by Satô (1958). The filtered traces, however, are given in figure 12, and the corresponding spectra in figure 13.

(e) New Guinea Earthquake. $G_{1}-G_{3}$ and $G_{2}-G_{4}$ combinations were used to obtain two sets of phase velocities for the same path. The original Pasadena strain seismogram along with spectra of these phases had been given by Satô (1958). Since ours is a completely independent analysis we are showing the filtered traces and spectra in figure 14 and figure 15, respectively. The phase velocities are listed in table 4.

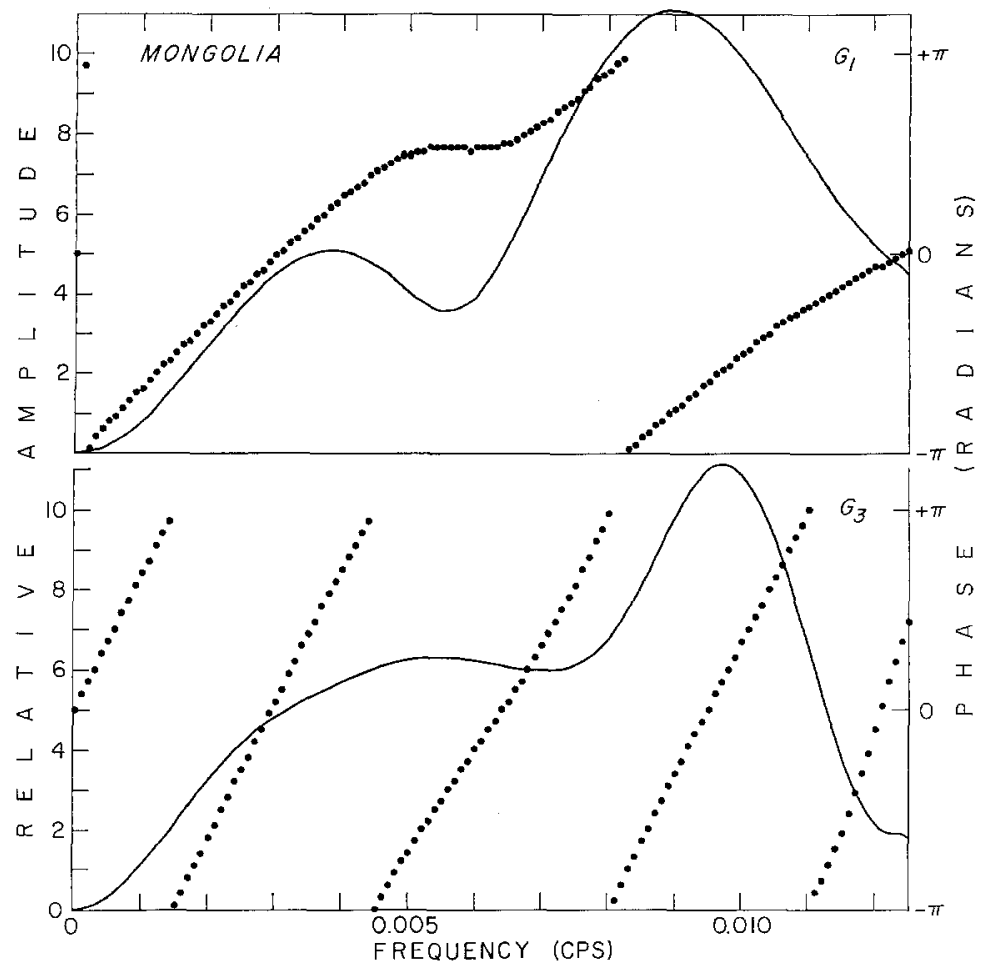

FiG. 5. Amplitude and phase spectra of Mongolia $\mathrm{G}_{1}$ and $\mathrm{G}_{3}$.

For the sake of an easy comparison, the phase velocities of Rayleigh waves are plotted in figure 16, and those of Love waves in figure 17.

\section{Analytic Expressions for Phase and Group Velocities}

The group velocities can be computed from the phase velocities, using the expression

$$
U=\frac{d \omega}{d k}=\frac{C}{1+\frac{T}{C} \frac{d C}{d T}}
$$

where $U=$ group velocity, $k=2 \pi / \lambda=$ wave number. The only difficulty in this computation arises from the differentiation of the phase velocity curve. This could 
TABLE 4

Phase Velocities of Love Waves

\begin{tabular}{|c|c|c|c|c|c|c|c|c|}
\hline \multirow{3}{*}{$\begin{array}{l}\text { Frequency } \\
\text { (cps) }\end{array}$} & \multirow{3}{*}{ Period (sec.) } & \multicolumn{7}{|c|}{ Phase Velocities $(\mathrm{km} / \mathrm{sec})$} \\
\hline & & \multirow{2}{*}{$\underset{\mathrm{G}_{3}-\mathrm{G}_{1}}{\text { Mongolia }}$} & \multirow{2}{*}{$\underset{\mathbf{G}_{s}-\mathbf{G}_{1}}{\text { Assam }}$} & \multirow{2}{*}{$\underset{\mathrm{G}_{4}-\mathrm{G}_{2}}{\text { Alaska- }}$} & \multirow{2}{*}{$\underset{\mathrm{G}_{4}-\mathrm{G}_{2}}{\text { Kamchatka }}$} & \multirow{2}{*}{$\begin{array}{c}\text { Alaska- } \\
\text { Wilkes } \\
\text { G }_{4}-G_{2}\end{array}$} & \multicolumn{2}{|c|}{ New Guinea } \\
\hline & & & & & & & $\mathrm{G}_{3}-\mathrm{G}_{1}$ & $\mathrm{G}_{4}-\mathrm{G}_{2}$ \\
\hline .0026 & 384.61 & 5.506 & & 5.509 & & & & \\
\hline .0027 & 370.37 & 5.452 & & & & & & \\
\hline .0028 & 357.14 & 5.403 & & 5.414 & & & & \\
\hline .0029 & 344.83 & 5.358 & & & & & & \\
\hline .0030 & 333.33 & 5.317 & & 5.331 & & 5.324 & & \\
\hline .0031 & 322.58 & 5.279 & & & & & & \\
\hline .0032 & 312.50 & 5.244 & & 5.258 & 5.218 & 5.274 & & \\
\hline .0033 & 303.03 & 5.211 & 5.180 & & & & & \\
\hline .0034 & 294.12 & 5.181 & 5.155 & 5.193 & 5.167 & 5.221 & & \\
\hline .0035 & 285.71 & 5.153 & 5.131 & & & & & \\
\hline .0036 & 277.78 & 5.126 & 5.109 & 5.137 & 5.119 & 5.171 & & \\
\hline .0037 & 270.27 & 5.102 & 5.089 & & & & & 5.134 \\
\hline .0038 & 263.16 & 5.078 & 5.070 & 5.089 & 5.076 & 5.123 & & 5.113 \\
\hline .0039 & 256.41 & 5.057 & 5.052 & & & & & 5.093 \\
\hline .0040 & 250.00 & 5.036 & 5.034 & 5.047 & 5.037 & 5.078 & & 5.074 \\
\hline .0041 & 243.90 & 5.017 & 5.018 & & & & & 5.055 \\
\hline .0042 & 238.09 & 4.998 & 5.002 & 5.010 & 5.002 & 5.037 & & 5.038 \\
\hline .0043 & 232.56 & 4.981 & 4.987 & & & & & 5.022 \\
\hline .0044 & 227.27 & 4.965 & 4.973 & 4.977 & 4.971 & 5.001 & & 5.007 \\
\hline .0045 & 222.22 & 4.949 & 4.958 & & & & & 4.993 \\
\hline .0046 & 217.39 & 4.934 & 4.945 & 4.948 & 4.942 & 4.968 & & 4.973 \\
\hline .0047 & 212.77 & 4.920 & 4.932 & & & & & 4.966 \\
\hline .0048 & 208.33 & 4.907 & 4.919 & 4.921 & 4.916 & 4.940 & & 4.953 \\
\hline .0049 & 204.08 & 4.895 & 4.907 & & & & & 4.942 \\
\hline .0050 & 200.00 & 4.882 & 4.894 & 4.896 & 4.891 & 4.914 & 4.942 & 4.930 \\
\hline .0052 & 192.31 & 4.860 & 4.872 & 4.874 & 4.869 & 4.891 & 4.918 & 4.909 \\
\hline .0054 & 185.19 & 4.840 & 4.851 & 4.853 & 4.848 & 4.870 & 4.897 & 4.889 \\
\hline .0056 & 178.57 & 4.821 & 4.832 & 4.834 & 4.829 & 4.851 & 4.877 & 4.871 \\
\hline .0058 & 172.41 & 4.804 & 4.814 & 4.816 & 4.810 & 4.834 & 4.859 & 4.854 \\
\hline .0060 & 166.67 & 4.789 & 4.797 & 4.800 & 4.791 & 4.818 & 4.842 & 4.839 \\
\hline .0062 & 161.29 & 4.774 & 4.780 & 4.785 & 4.772 & 4.804 & 4.826 & 4.824 \\
\hline .0064 & 156.25 & 4.760 & 4.765 & 4.771 & 4.754 & 4.792 & 4.812 & 4.811 \\
\hline .0066 & 151.52 & 4.748 & 4.750 & 4.758 & 4.737 & 4.781 & 4.801 & 4.798 \\
\hline .0068 & 147.06 & 4.736 & 4.736 & 4.746 & 4.723 & 4.770 & 4.787 & 4.786 \\
\hline .0070 & 142.86 & 4.724 & 4.723 & 4.734 & 4.711 & 4.761 & 4.775 & 4.775 \\
\hline .0072 & 138.89 & 4.713 & 4.710 & 4.724 & 4.701 & 4.752 & 4.765 & 4.765 \\
\hline .0074 & 135.14 & 4.703 & 4.698 & 4.714 & 4.692 & 4.744 & 4.755 & 4.755 \\
\hline .0076 & 131.58 & 4.693 & 4.686 & 4.704 & 4.685 & 4.736 & 4.745 & 4.746 \\
\hline .0078 & 128.21 & 4.683 & 4.676 & 4.695 & 4.680 & 4.729 & 4.736 & 4.737 \\
\hline .0080 & 125.00 & 4.674 & 4.666 & 4.686 & 4.674 & 4.722 & 4.728 & 4.729 \\
\hline .0082 & 121.95 & 4.665 & 4.657 & & & & & \\
\hline .0084 & 119.05 & 4.657 & 4.648 & & & & 4.713 & 4.714 \\
\hline .0086 & 116.28 & 4.648 & 4.640 & & & & & \\
\hline .0088 & 113.64 & 4.642 & 4.633 & & & & 4.699 & 4.701 \\
\hline .0090 & 111.11 & 4.635 & 4.626 & & & & & \\
\hline .0092 & 108.70 & 4.628 & 4.620 & & & & 4.687 & 4.689 \\
\hline .0094 & 106.38 & 4.621 & 4.614 & & & & & \\
\hline .0096 & 104.17 & 4.615 & 4.609 & & & & 4.677 & 4.678 \\
\hline
\end{tabular}


TABLE 4 (Cont.)

\begin{tabular}{|c|c|c|c|c|c|c|c|c|}
\hline \multirow{3}{*}{$\begin{array}{l}\text { Frequency } \\
\text { (cps) }\end{array}$} & \multirow{3}{*}{ Period (sec.) } & \multicolumn{7}{|c|}{ Phase Velocities $(\mathrm{km} / \mathrm{sec})$} \\
\hline & & \multirow{2}{*}{$\underset{\mathrm{G}_{3}-\mathrm{G}_{2}}{\text { Mongolia }}$} & \multirow{2}{*}{$\begin{array}{c}\text { Assam } \\
\mathrm{G}_{\sigma}-\mathrm{G}_{\lambda}\end{array}$} & \multirow{2}{*}{$\begin{array}{c}\text { Alaska- } \\
\text { Pasadena } \\
\mathrm{G}_{4}-\mathrm{G}_{2}\end{array}$} & \multirow{2}{*}{$\underset{\mathbf{G}_{4}-\mathrm{G}_{2}}{\text { Kamchata }}$} & \multirow{2}{*}{$\begin{array}{l}\text { Alaska- } \\
\text { Wilkes } \\
\mathrm{G}_{4}-\mathrm{G}_{2}\end{array}$} & \multicolumn{2}{|c|}{ New Guinea } \\
\hline & & & & & & & $\mathrm{G}_{3}-\mathrm{G}_{1}$ & $\mathrm{G}_{4}-\mathrm{G}_{2}$ \\
\hline .0098 & 102.04 & 4.609 & 4.603 & & & & & \\
\hline .0100 & 100.00 & 4.603 & 4.598 & & & & 4.667 & 4.668 \\
\hline .0102 & 98.04 & 4.597 & 4.593 & & & & & \\
\hline .0104 & 96.15 & 4.592 & 4.589 & & & & 4.659 & 4.659 \\
\hline .0106 & 94.34 & 4.587 & 4.585 & & & & & \\
\hline .0108 & 92.59 & 4.582 & 4.580 & & & & 4.651 & 4.651 \\
\hline .0110 & 90.91 & 4.577 & 4.576 & & & & & \\
\hline .0112 & 89.29 & 4.572 & 4.572 & & & & 4.643 & 4.643 \\
\hline .0114 & 87.72 & 4.568 & 4.568 & & & & & \\
\hline .0116 & 86.21 & 4.564 & 4.565 & & & & 4.635 & 4.637 \\
\hline .0118 & 84.75 & 4.559 & 4.561 & & & & & \\
\hline .0120 & 83.33 & 4.555 & 4.557 & & & & 4.622 & \\
\hline .0124 & 80.64 & & 4.550 & & & & 4.609 & \\
\hline .0128 & 78.12 & & 4.543 & & & & & \\
\hline .0132 & 75.76 & & & & & & 4.595 & \\
\hline .0140 & 71.43 & & & & & & 4.585 & \\
\hline .0148 & 67.57 & & & & & & 4.576 & \\
\hline .0156 & 64.10 & & & & & & 4.568 & \\
\hline .0164 & 60.98 & & & & & & 4.560 & \\
\hline .0172 & 58.14 & & & & & & 4.553 & \\
\hline .0180 & 55.56 & & & & & & 4.546 & \\
\hline
\end{tabular}

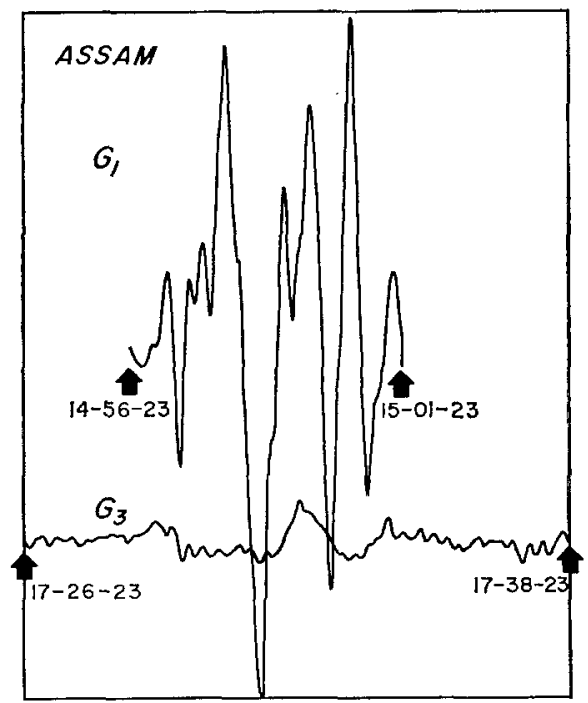

FIg. 6. Unfiltered traces of Pasadena strain recordings of $\mathrm{G}_{1}$ and $\mathrm{G}_{3}$ from the Assam earthquake. 
be accomplished by either a direct numerical differentiation or representing the phase velocity curve by an analytic function and computing the derivatives of this function. We chose to fit a polynomial of the form $P_{n}(T)=\sum_{i=0}^{n} a_{i} X(T)$ to the data where the coefficients were determined by the method of least squares. Different polynomials of order $n=4$ to $n=9$ were used. The lower order polynomials miss the finer variations in the data, whereas the higher order polynomials follow any scattering that may be present in the original data resulting in undesired oscillations. The group velocities shown in figures 16 and 17 are the average values

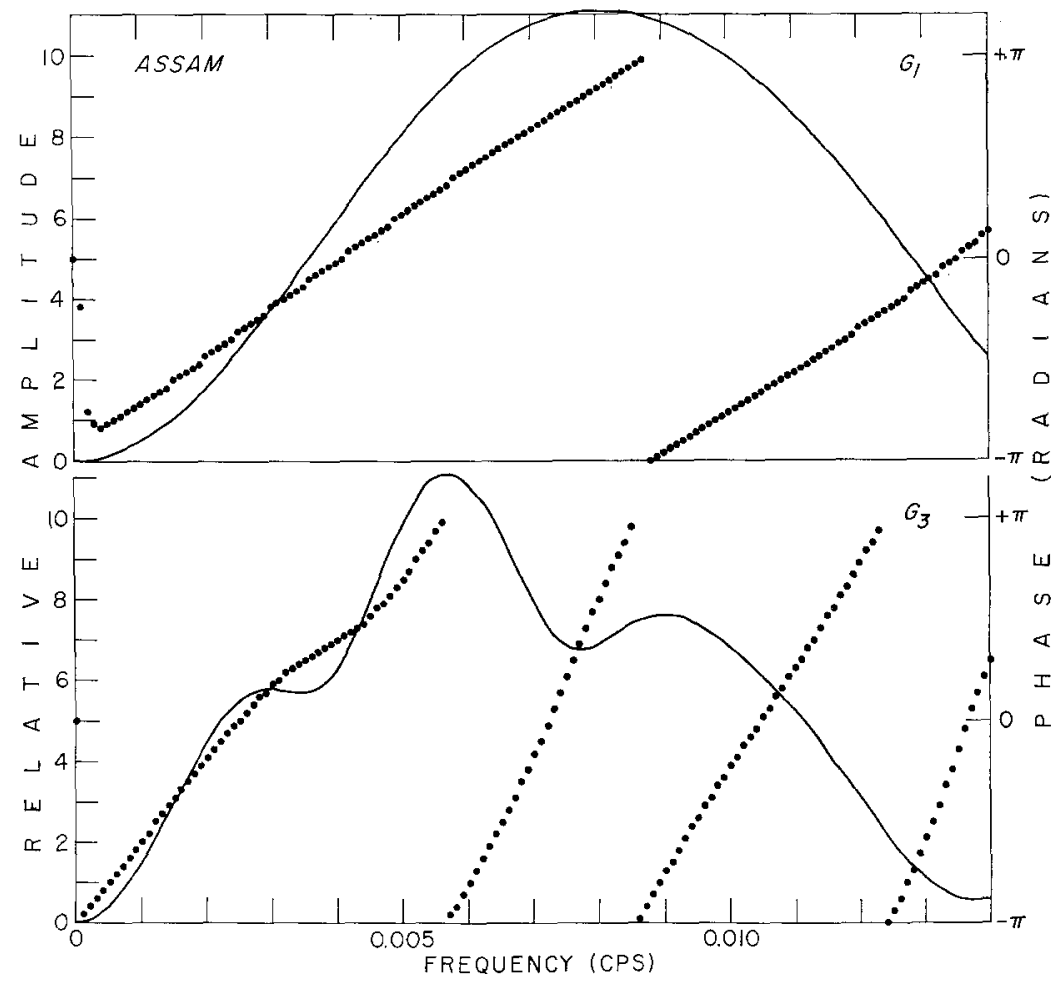

FIG. 7. Spectra of $\mathrm{G}_{1}$ and $\mathrm{G}_{3}$ from the Assam earthquake.

derived from two or more different order polynomials. It is important to mention that differentiation magnifies greatly the error that may be present in the phase velocity data, and the group velocities computed by this method are much less reliable than the phase velocities. In spite of this, these group velocities agree reasonably well with the velocities computed directly from the filtered records. The value of the method of computing the group velocity from the phase velocities, is greater for Love waves than for Rayleigh waves. The group velocity curve of Love waves is nearly flat from $T=100$ to $T=300$ seconds. The wave disperses very little and tends to preserve its initial shape. Unless one performs an extensive amount of narrow band filtering, it is very difficult to compute group velocities for different periods. This is one of the reasons for the greater scatter in the time domain meas- 


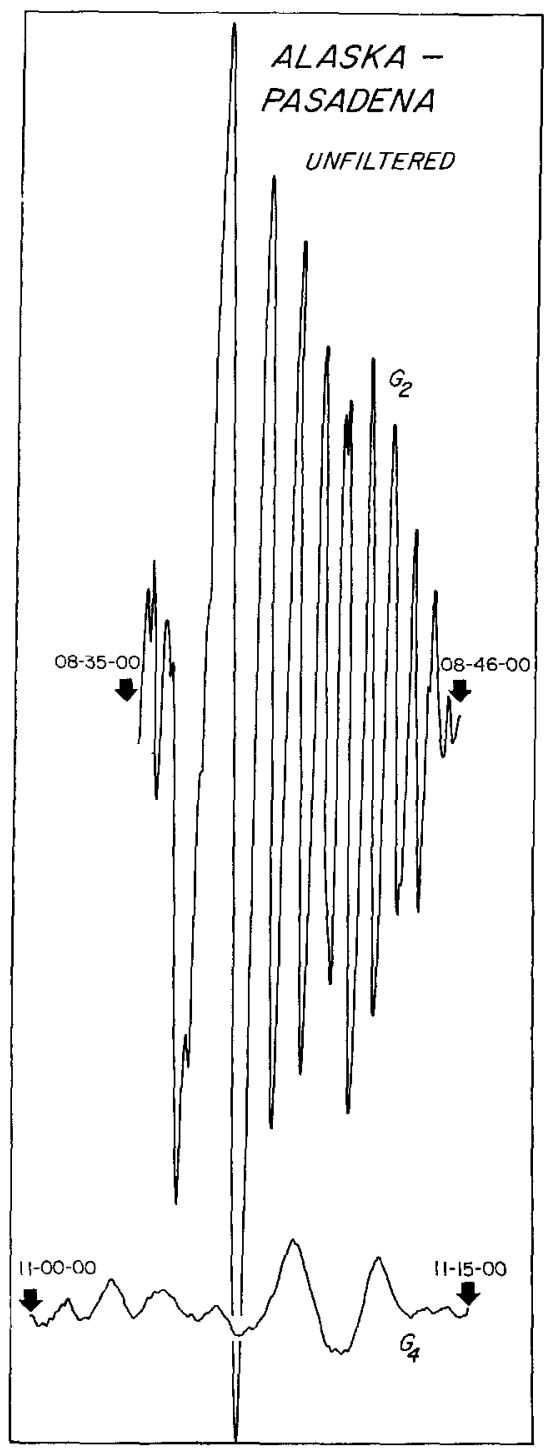

FIG. 8 a

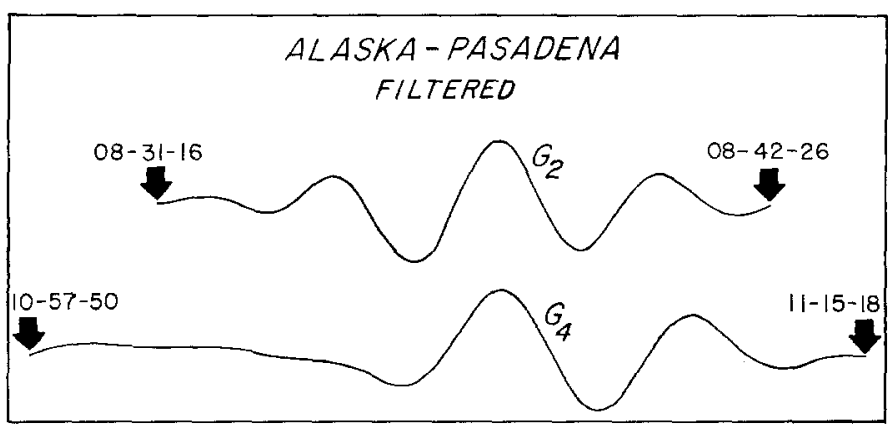

FIG. $8 \mathrm{~b}$

Fig. 8. Unfiltered (a) and low-pass filtered (b) $G_{2}$ and $G_{4}$ phases (E-W component) from the Alaska earthquake recorded at Pasadena by Press-Ewing seismograph system. (Amplitude scales are not uniform.) 
urements of phase and group velocities of Love waves in this particular period range (see Brune, Benioff and Ewing, 1961, figure 7).

For more general use, simple functions can be fit to phase velocity data. For Rayleigh waves, one may write (Ben-Menahem and Toksöz, 1962)

$$
C(T)=3.85+0.0046 T-0.25 \sin (0.01 T+0.28)
$$

$$
100<T<500
$$

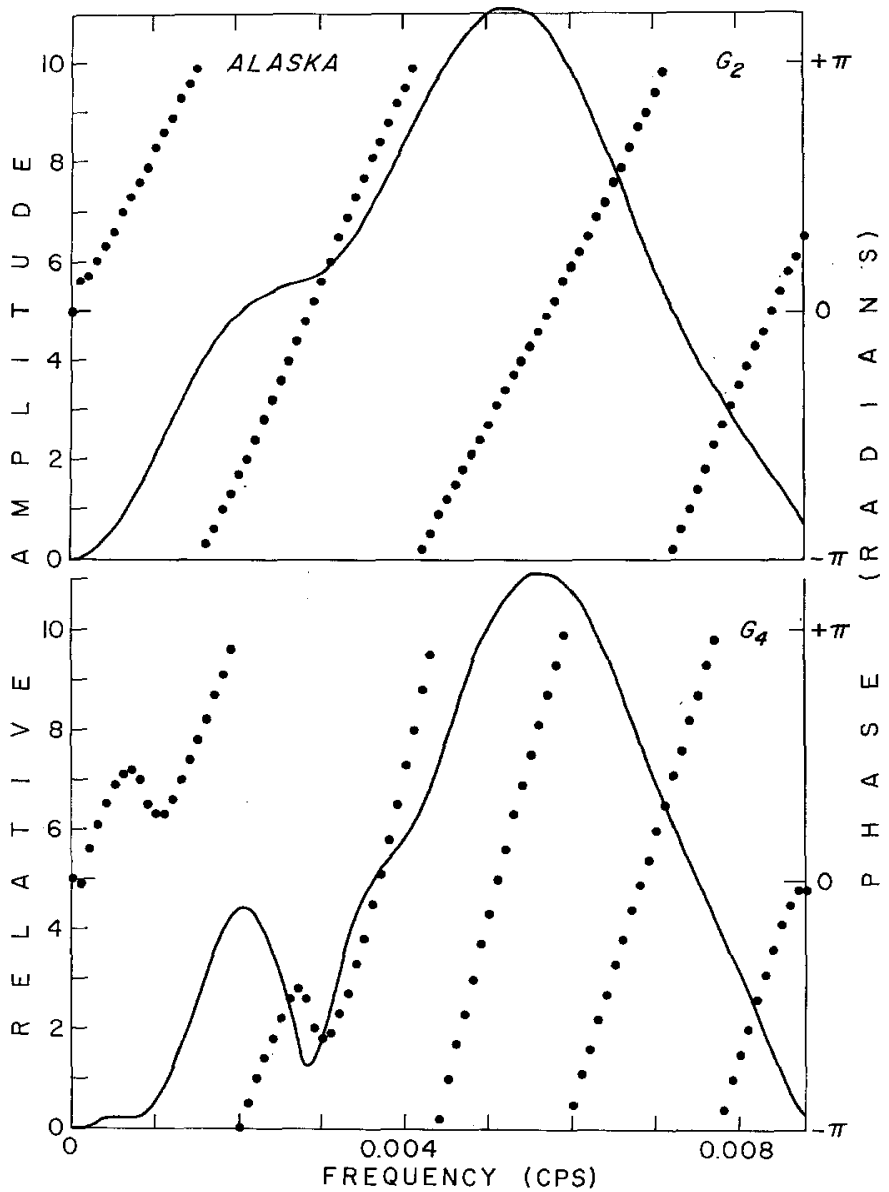

FIG. 9. Amplitude and phase spectra of Pasadena recodings of $G_{2}$ and $G_{4}$ from the Alaska earthquake.

which is a good approximation. Also, the group velocities obtained from the above expression using eq. (4) agree with the measured values. For the Love waves one may utilize the property of the almost-constancy of the group velocity in the plateau of the dispersion curve to derive an expression for the phase velocity (Satô, 1958). Differentiating the group velocity, and setting $d U / d T=0$, one obtains the differential equation

$$
2\left(\frac{d C}{d T}\right)^{2}=C \frac{d^{2} C}{d T^{2}}
$$




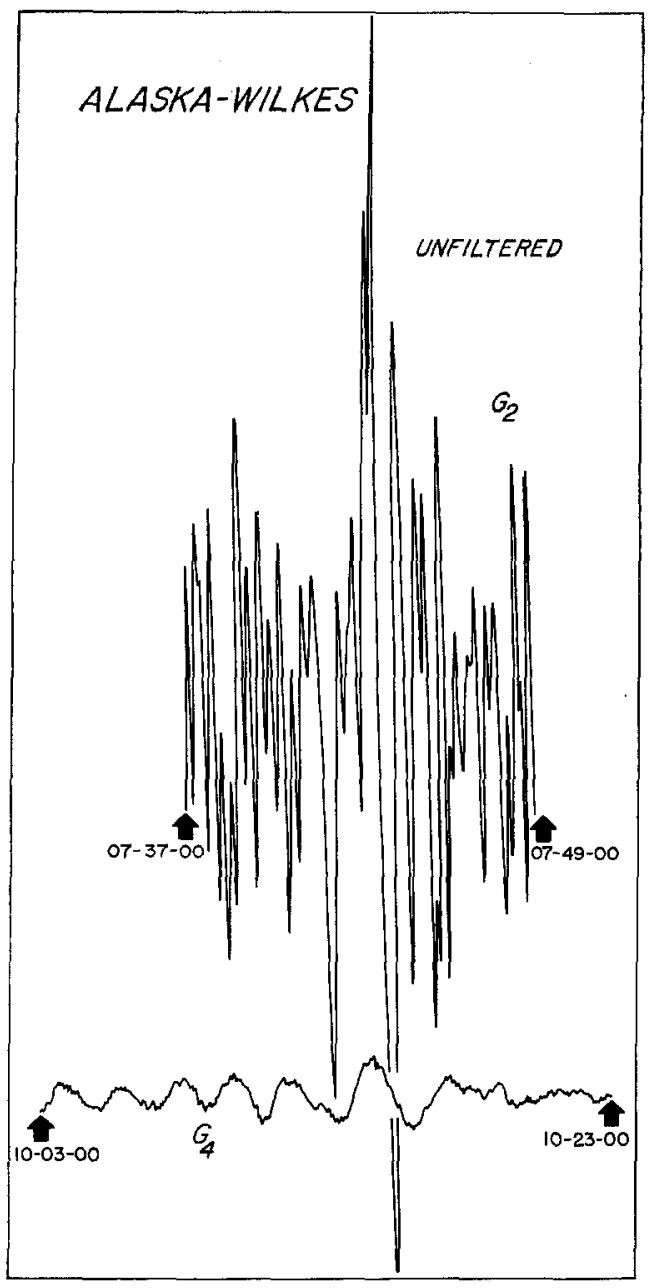

FIg. 10a

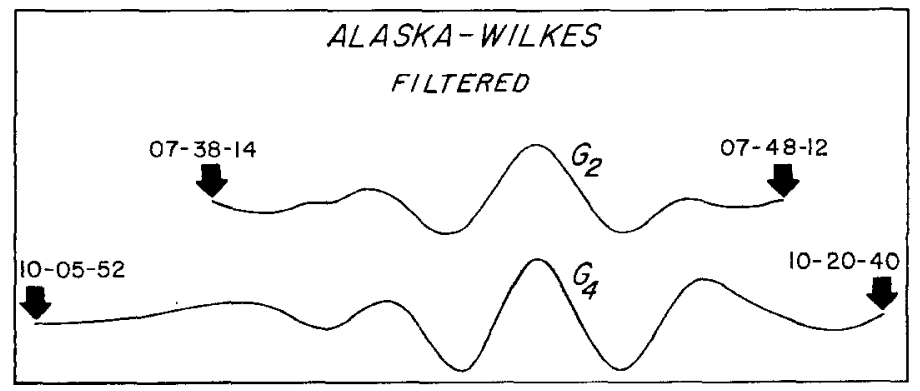

FIG. $10 \mathrm{~b}$

Fig. 10. Unfiltered (a) and low-pass filtered (b) $G_{2}$ and $G_{4}$ phases (N-S component) from the Alaska earthquake recorded at Wilkes by Press-Ewing seismograph. (Arbitrary amplitude scales.) 


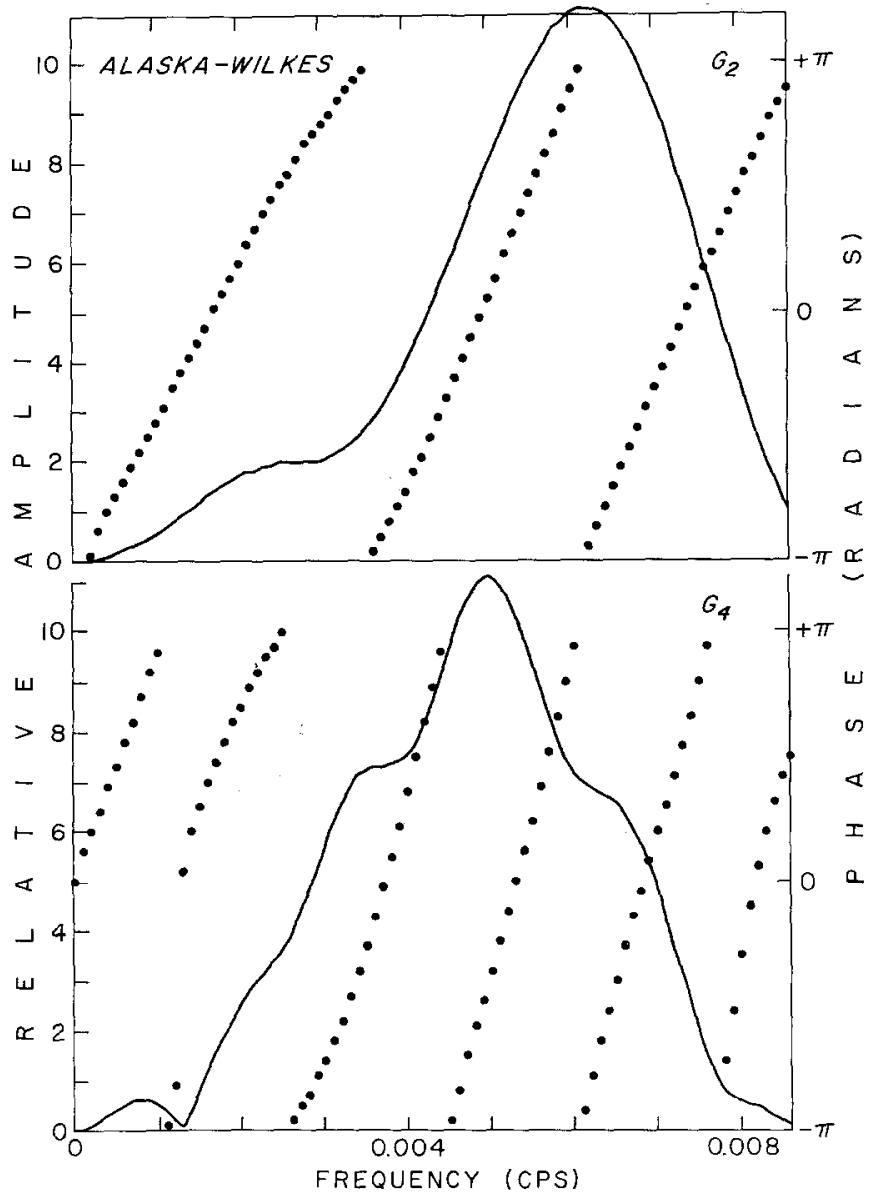

FIG. 11. Spectra of $G_{2}$ and $G_{4}$ from the Alaska earthquake recorded at Wilkes.

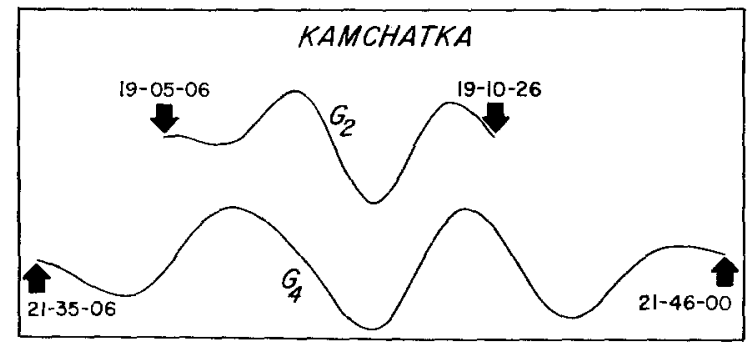

FIG. 12. Filtered traces of Pasadena N-S strain recordings of $G_{2}$ and $G_{4}$ from the Kamchatka earthquake. (Arbitrary amplitude scales.)

A solution to this equation is,

$$
C=\frac{U_{0}}{1-\alpha T}
$$

where $U_{0}$ is the constant value of the group velocity. It should be noted that expression (6) is approximate, since the group velocity in the plateau is not a true 


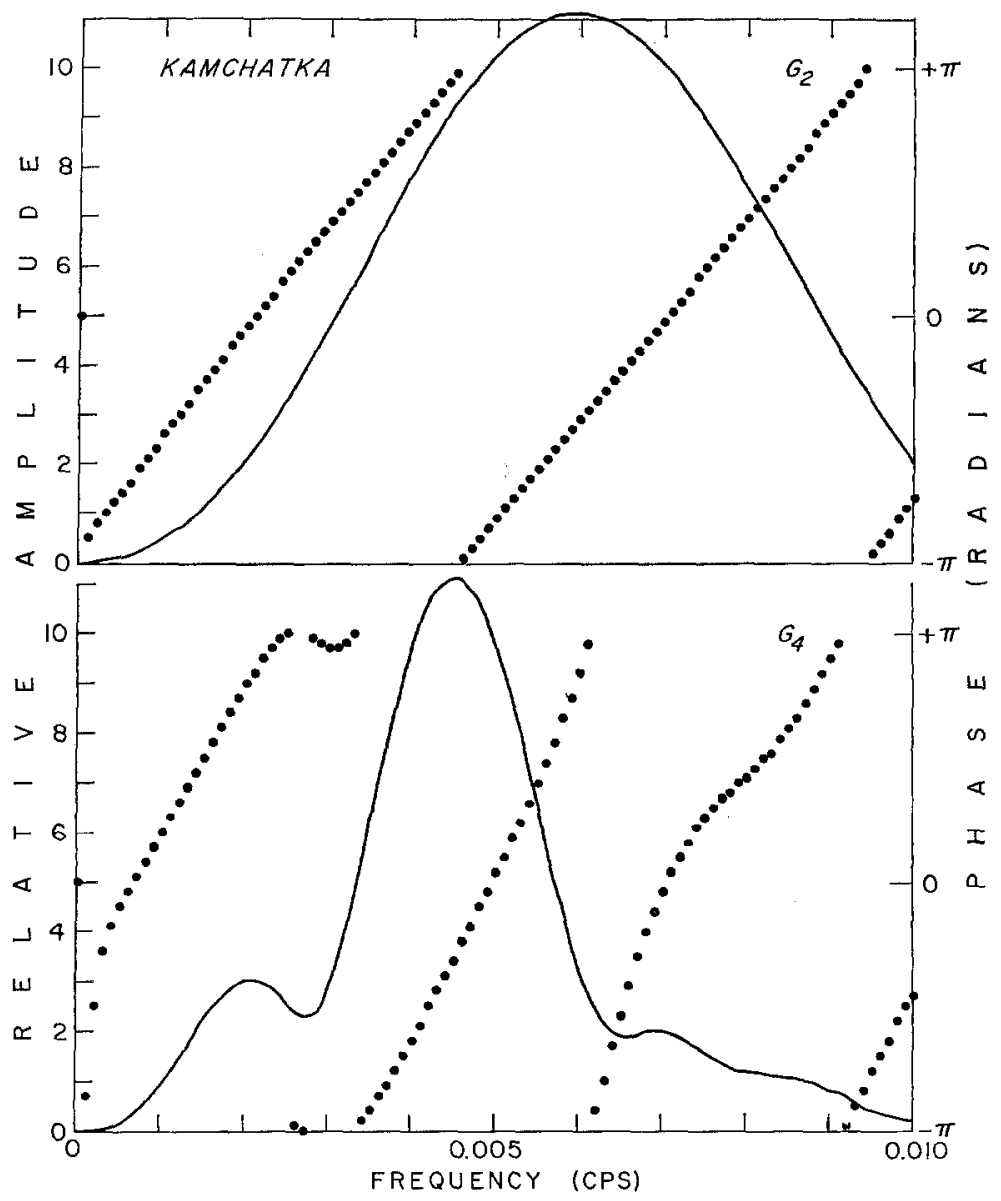

FIG. 13. Spectra of $\mathrm{G}_{2}$ and $\mathrm{G}_{4}$ from Kamchatka.

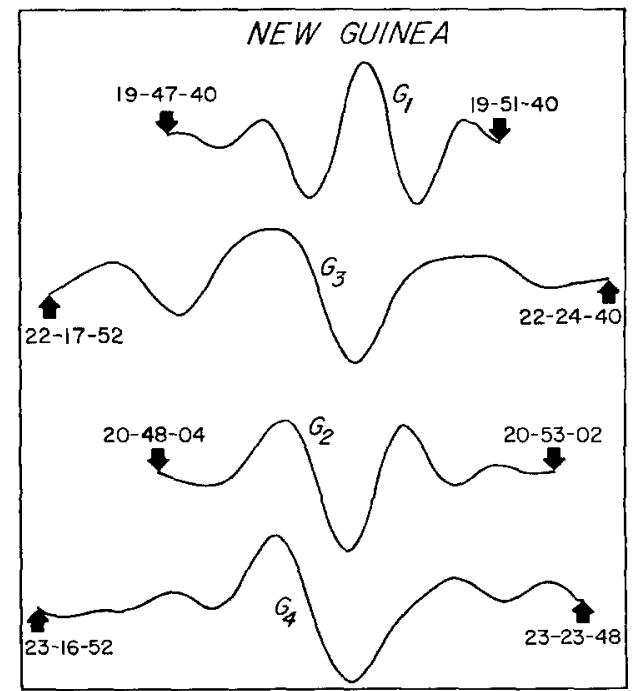

Frg. 14. Filtered traces of Pasadena N-S strain recordings of $G_{1}, G_{2}, G_{3}$, and $G_{4}$ traces from the New Guinea earthquake. (Arbitrary amplitude scales.) 

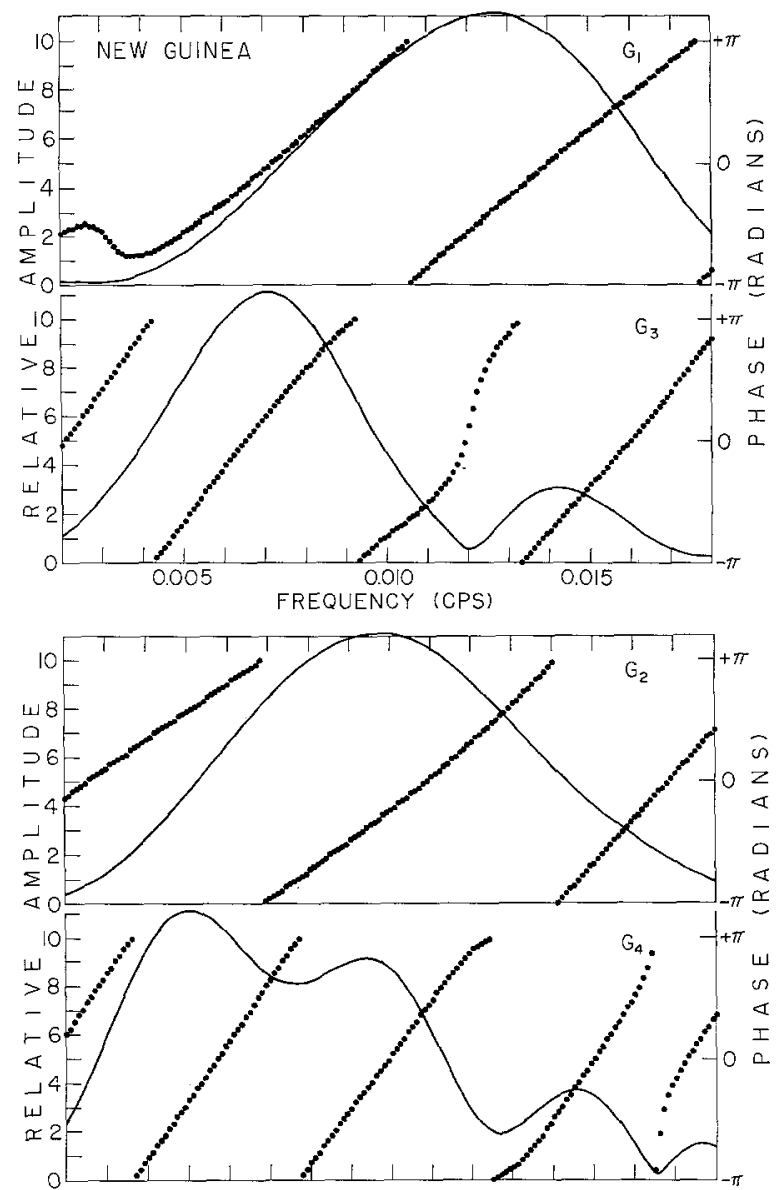

FIG. 15. Amplitude and phase spectra of $G_{1}, G_{2}, G_{3}$, and $G_{4}$ from New Guinea.

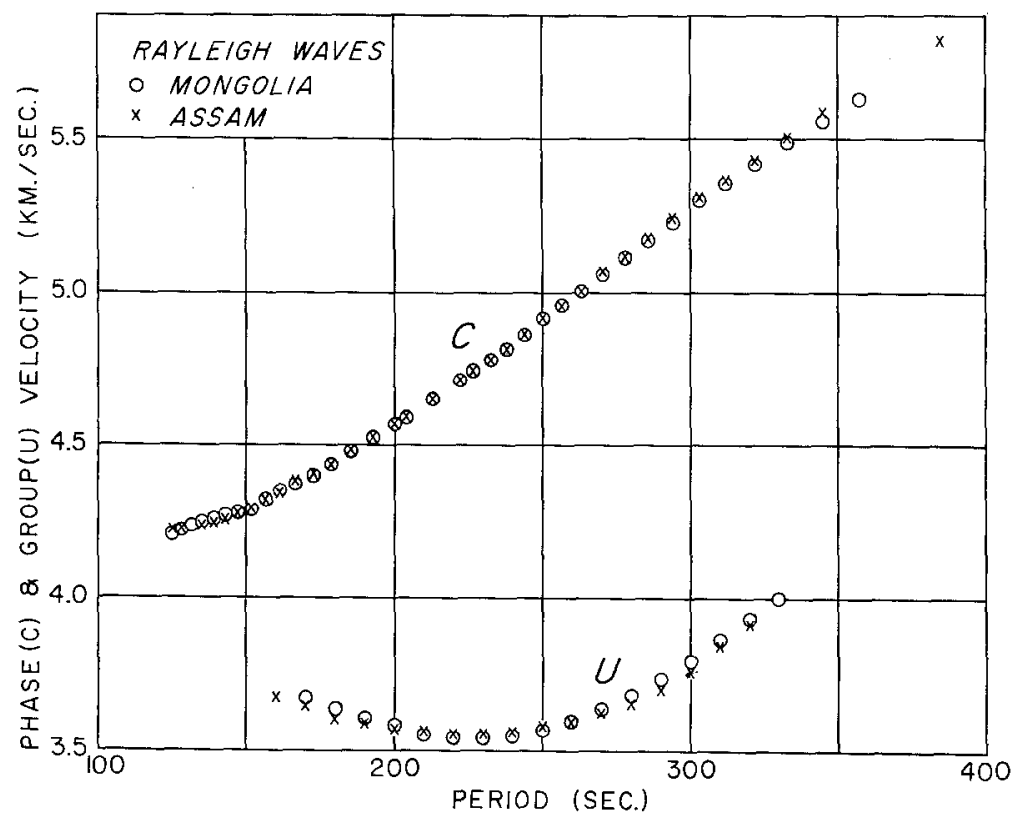

Frg. 16. Phase and group velocities of Rayleigh waves for Mongolia-Pasadena and Assan Pasadena great circle paths. Group velocities are derived from phase velocities. 
constant but varies slowly with the period. The values $U_{0}=4.37$ and $\alpha=5.35 \times$ $10^{-4}$ give a reasonably good fit to the observed phase velocities (New Guinea excepted) between $T=100$ and $T=300$ seconds. This indicates that the group velocity curve is nearly constant over that period range.

\section{Discusston on the Accuracy of the Results}

The phase velocities listed in tables 2 and 3 are probably within 0.5 per cent of the correct value. Since the absolute values are not known, reproducibility and the

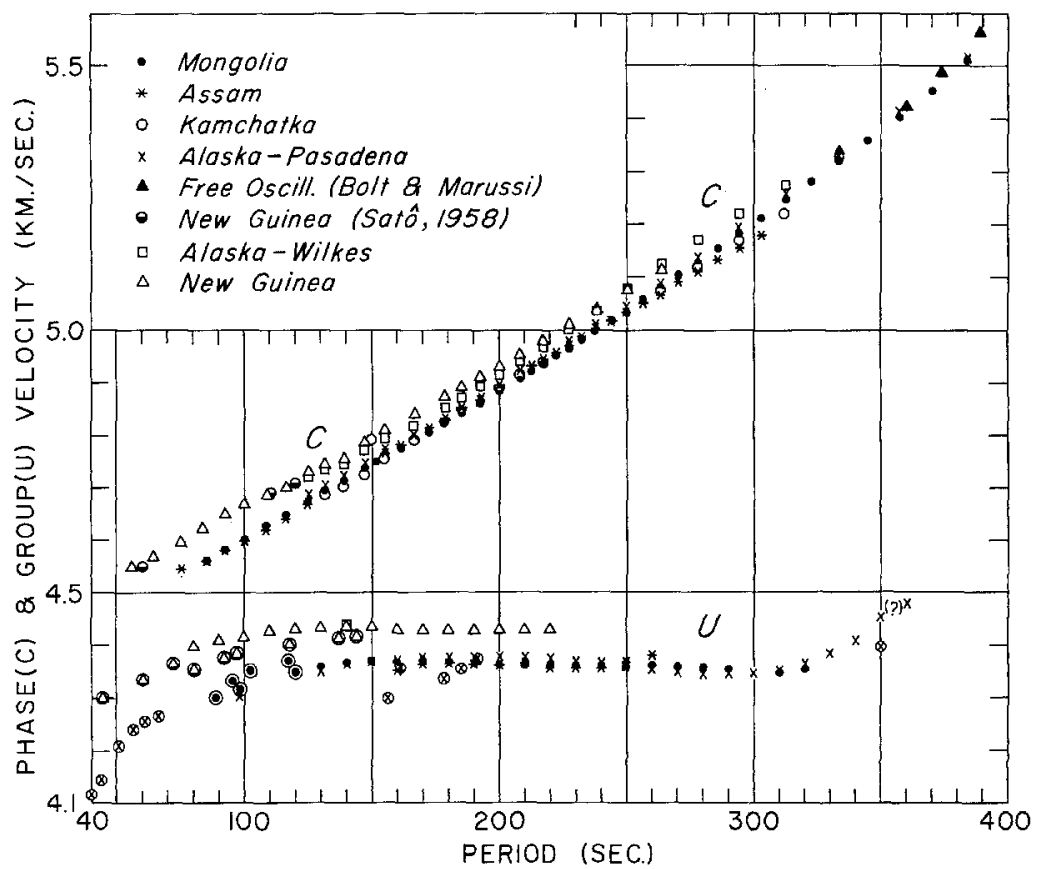

FIG. 17. Phase and group velocities of Love waves over several great circle paths. The group velocities with circles around the symbol are measured directly from the seismogram. Others derived from the phase velocities.

agreement between different measurements are the only basis for the judgment of accuracy. For the Mongolian and Assam earthquakes phase velocities agree with less than $.02 \mathrm{~km} / \mathrm{sec}$ discrepancy, over a wide frequency range, for both Love waves and Rayleigh waves. Phase velocities of Love waves from the Alaska earthquake (through Pasadena) agree with those of Assam and Mongolia, while Kamchatka yields slightly lower phase velocities. The New Guinea-Pasadena path has the highest values of phase velocities among all the paths. As to the reliability of these results, we can point out that the agreement between $G_{1}-G_{3}$ and $G_{2}-G_{4}$ combinations is excellent, and these results are also in accord with Satô's measurements as given by Brune, Benioff, and Ewing (1961). It should be noted here that the New GuineaPasadena great circle path is quite different from the other paths, being almost entirely oceanic. Alaska-Wilkes great circle phase velocities are between those of New Guinea and Mongolia. The slope of the phase velocity curve, however, is 
greater than those of others shown in figure 17. This discrepancy may be due to the larger error in Wilkes phase velocities compared to the others. It is also possible that the Alaska-Wilkes path represents a considerably different structure than the other paths.

The group velocities for different paths vary in a manner similar to the variation of phase velocities. For close paths (Mongolia, Alaska, Assam), the group velocities are in agreement. The New Guinea-Pasadena path, on the other hand, has considerably higher group velocities compared to others. In computing the group velocities from the seismograms, no attempt was made to correct for source effects. In the case of major earthquakes, the finiteness effect could be significant, and is given by the following expressions (Press, Ben-Menahem, Toksöz, 1961)

$$
U^{\prime}=\frac{U}{1+\frac{b}{2 \Delta}\left(\frac{U}{V_{f}}-\cos \theta_{0}\right)} \approx U\left[1-\frac{b}{2 \Delta}\left(\frac{U}{V_{f}}-\cos \theta_{0}\right)\right]
$$

where $U=d \omega / d k, U^{\prime}=\Delta / t$ is the group velocity as measured from the seismogram, $b=$ fault length, $v_{f}=$ rupture velocity along the fault, and $\theta_{0}=$ azimuthal angle. This could explain the apparent delay of the arrival of $G_{1}$ of the Assam earthquake by as much as $170 \mathrm{sec}$ (arrival group velocity of $4.07 \mathrm{~km} / \mathrm{sec}$ instead of the usual $4.35-4.40 \mathrm{~km} / \mathrm{sec})$.

\section{Errors in Phase Velocity Measurements}

It is important that the sources of error in phase velocity measurements are clarified before one can judge the accuracy of various measurements. Here we will briefly discuss the errors involved in Fourier analysis and direct measurement methods.

\section{Fourier Analysis Method}

In the phase velocity measurement with the Fourier analysis method using equation (2) only the phase term can be in error, provided the integer $N$ is chosen correctly. The great circle distance may have the uncertainty of $10 \mathrm{~km}$ but this will only result in 0.025 per cent error in phase velocity since

$$
\frac{\partial C}{C}=\frac{\partial \Delta}{\Delta}, \quad \Delta \approx 40,000 \mathrm{~km}
$$

The error in the phases is due to interference, noise, digitizing, and numerical inaccuracies. The latter two quantities are random errors and will show as scattering in the data. The extent of this error can be estimated from the behaviour of the phase spectra, and we find that in the frequency range of interest no measurable scattering occurs. Errors that may result from "window-shaping", and inadequate detrending are discussed by Gratsinsky (1962), but these can be avoided by proper care in the analysis. The interference (superimposition of two similar signals with a time delay, or two different signals with power in the same frequency range) is a 
serious problem in Fourier analysis. A typical indication of such interference is the presence of power-minima in the amplitude spectra accompanied by minima or turning points in the phase spectra (Pilant, 1962). The effect of the interference on the phases, and the error introduced is difficult to evaluate without knowing the true nature of the interference. In the case of two similar signals, one of which is delayed relative to the other by $\Delta t$, the error in the phase is

$$
\Delta \phi=\frac{\alpha \sin \omega \Delta t}{\omega}
$$

where $\alpha$ is the normalized amplitude of the delayed signal. The amplitude spectrum of the original pulse is modulated by the factor $(1+\alpha \cos \omega \Delta t)$. The maxima and minima in the amplitude spectrum corresponds to $(1+\alpha)$ and $(1-\alpha)$ from which $\alpha$ can be found. The maximum phase error, $|\Delta \phi|_{\max }=\alpha \Delta t$, can be computed if $\Delta t$ is known.

The error in the phase velocity due to phase inaccuracies is found by differentiating equation (2) with respect to $\delta \phi$.

$$
\frac{\partial C}{C}=-\frac{C T}{\Delta} \partial(\delta \phi)
$$

On the assumption that $\partial(\delta \phi)=0.4$, the error in the phase velocity at a period of 100 seconds is less than 0.5 per cent. At longer periods, the error in the phases is much less than 0.4 circle. An important point should be restated here: errors in phase differences are due to interference and contamination introduced during propagation only, since the phase variations of the source are canceled when two successive passages of odd or even order waves are used.

\section{Phase Velocities Measured Directly From the Seismogram}

In the above discussion we pointed out that the Fourier analysis method of determining phase velocity is an exact method, and the only error results from the contamination of the phases. Time domain measurements, however, have theoretical as well as practical limitations. We will present here a brief discussion of these limitations.

The idea behind the method of direct measurement of phase velocities and initial phases from the seismogram is that one may associate a sine wave with each peak or trough of a dispersed wave train, which apart from the Airy phase, is shifted by $\pi / 4$ with respect to the group arrival (Brune, Nafe, and Oliver, 1960; Nafe and Brune, 1960). Consider a surface wave of order $n$, which originates at an arbitrary source inside the isotropic, layered spherical earth. A component of the surface displacements at a station $(\theta, \Delta)$ on the sphere at time $t$ is given by

$$
f_{i}(\theta, \Delta, t)=\frac{A(\theta)}{2 \pi} \int_{-\infty}^{\infty} e^{i \omega t} S\left(\omega, \alpha_{j}\right) G\left(\omega, \beta_{k}\right)\left\{\begin{array}{c}
W_{n}(\cos \eta) \\
\frac{\partial W_{n}(\cos \eta)}{\partial \eta}
\end{array}\right\} d \omega
$$


where $f_{i}$ is a component of the surface displacement, $\theta$ is the azimuth of the station with respect to the source, $S$ is the source spectrum which depends on the parameters $\alpha_{j}, G$ is the medium response which depends on the parameters $\beta_{k}, A(\theta)$ is the azimuthal function of the source, and $W_{n}$ is defined by

$$
W_{n}(\cos \eta)=P_{n}+i \frac{2}{\pi} Q_{n} \approx \sqrt{\frac{2}{n \pi \sin \eta}} g(\eta) e^{i\left[n(n+1 / 2)-x-\frac{\pi}{4}\right]}
$$

The asymptotic form holds when

$$
n+\frac{1}{2}=k R_{0} \gg 1, \quad \eta_{0}<\eta<\pi-\eta_{0}, \quad 0<\eta_{0} \leqq \frac{\pi}{6}
$$

where

$$
R_{0} \eta=\Delta, \quad x=\tan ^{-1} \frac{\cot \eta}{8 n(1-n / 4)}
$$

Inserting (13) in (12) and evaluating (12) by the method of stationary phase with the time $t$ in the role of the large parameter, one finds:

$$
\begin{aligned}
{\left[f_{i}(\theta, \Delta, t)\right]_{m} } & =\frac{A(\theta)}{2 \pi} \sqrt{\frac{2 \pi}{t\left|\frac{d^{2} \omega}{d k^{2}}\right|}} \frac{N\left(\omega_{0}\right)}{\sqrt{R_{0} \sin \Delta_{1}}} \\
\cdot & \exp i\left[\omega_{0} t-\Delta_{m} k+\frac{\pi}{4} \pm \frac{\pi}{4}+\frac{\pi}{2}(m-1)+\phi\left(k_{0}\right)\right]\left\{1+i \epsilon_{0}\right\}
\end{aligned}
$$

$\pi / 2(m-1)$ is the polar phase shift, $R_{0}$ is the mean radius of the earth, $\Delta$ is the epicentral distance, $k$ is the wave number, $\omega_{0}$ is the value of $\omega$ at the point of stationary phase and is given by the intersection of the group velocity curve with the line $U=\frac{\Delta_{m}}{t}, \phi\left(k_{0}\right)$ is the initial-phase function, $\epsilon_{0}$ is the magnitude of the first correction term. The transition from (12) to (14) is valid only if:

1. $t$ is large enough to ensure a fully dispersed wave-train.

2. The vicinity of the polar region in the source coordinates is excluded.

3. Neither the source-function nor the layering function vary rapidly as a function of frequency.

4. $d^{2} \omega_{0} / d k_{0}^{2} \neq 0$, that is, the frequency $\omega_{0}$ is not too near an extremum of the group-velocity curve.

5. The 'Pekeris-condition' holds (Pekeris, 1948);

$$
\epsilon_{0}=\left|\frac{1}{\Delta_{m}}\left[-\frac{5}{24} \frac{(\ddot{k})^{2}}{(\ddot{k})^{3}}+\frac{\ddot{k}}{8(\ddot{k})^{2}}\right]\right| \ll 1, \quad \dot{k}=\frac{d k}{d \omega}, \ddot{k} \neq 0
$$

6. Only one branch of the dispersion curve is considered, i.e. only one solution of $U=\Delta_{m} / t$ is taken.

The 'Pekeris-condition' introduces an additional phase of $\tan ^{-1} \epsilon_{0}$, and the phase 
associated with each group-arrival on the record will be shifted by the amount $\tan ^{-1} \epsilon_{0}$ with respect to the group. To evaluate this phase one can express the Pekeris-condition in terms of $\dot{U}=d U / d w$, and obtain for the leading term:

$$
\tan ^{-1} \epsilon_{0} \approx \frac{1}{12} \frac{1}{\Delta_{m}}\left|\frac{d U}{d \omega}\right|
$$

The percentage error in the phase velocity due to this phase will be $\frac{1}{2 \pi}\left(\frac{\lambda}{\Delta_{m}}\right)^{2} \frac{T}{C}$ $\left|\frac{d U}{d T}\right|$ which is negligible for periods in the region $100-700$ seconds.

In addition to the theoretical restrictions listed above there are experimental errors due to the inability of reading the periods exactly, and the errors introduced in averaging where the periods are not matched exactly. Let us assume that two peaks, one with period $T_{1}$ and the other with $T_{2}$, are correlated. The average period is defined as $\bar{T}=\left(T_{1}+T_{2}\right) / 2$ and the phase velocity is computed for this average assuming that $C(\bar{T})=\bar{C}(T)$. The error involved in this interpolation can be obtained using the results of Savarensky (1959). Leaving out the algebra involved in this process, the expression for phase velocity including the first correction term is:

$$
\bar{C}(T) \approx C(\bar{T})\left[1-\frac{\bar{C}^{2}}{\bar{U}^{2}}\left(\frac{\bar{C}}{\bar{U}}-1\right)\left(\frac{T_{2}-T_{1}}{T_{2}+T_{1}}\right)^{2}\right] .
$$

The second term in the brackets is the error resulting from taking the arithmetic mean to determine the average periods.

The error that results from inaccuracies in reading the time and periods is more serious than the other sources of error. When the true period $T_{0}$ is determined erroneously to be $T_{1}$, the computed phase velocity is taken to be $\bar{C}\left(T_{1}\right)$ rather than $C\left(T_{0}\right) . \bar{C}\left(T_{1}\right)$, however, differs from the true phase velocity at period $T_{1}, C\left(T_{1}\right)$, because of the propagation time $t$ in the expression for phase velocity. In determining $\bar{C}\left(T_{1}\right), t=t_{0}$ was used instead of $t=t_{1}$. The first order error in reading the period can be written as

$$
\frac{\partial C}{C}=\frac{\frac{\partial t}{\partial T} d T}{t-T\left(N-\frac{1}{2}\right)}
$$

$(\partial t / \partial T) d T$ is not the error in reading the time $t$ inaccurately, but is the error caused by assigning a wrong propagation time to a given period. The magnitude of this error depends on the slope of the dispersion curve.

\section{Conclusions}

Phase velocities of mantle Love and Rayleigh waves can be measured accurately over a wide frequency range from the phase spectra of repeated passages of the same 
wave train. It is very important, however, that the pulse is free of interference and contamination; otherwise, undetermined errors will be introduced in the phases, and hence in the phase velocities. If properly used, the Fourier analysis method is especially valuable for application to mantle Love waves where the group velocity is nearly constant over a wide range of frequencies, and the wave retains a pulselike shape.

The phase velocities of Love waves over different great circle paths are in good agreement where the paths are close. Where the paths are quite different, there are consistent variations in phase velocities, which are more pronounced at shorter periods. The phase velocities are higher over paths which are almost completely oceanic (New Guinea) than those over the paths that cross the continents. This shows that the upper mantle velocities vary laterally, and may be different under the oceans from those under the continents. Such a variation has also been observed from velocities of Rayleigh waves (Dorman, Ewing, and Oliver, 1960; Aki and Press, 1961; Kuo, Brune, and Major, 1962). We are, at the present, fitting structures to the observed phase velocities to determine the extent of variations over different paths.

The group velocity curve of Love waves has a wide plateau between the periods of 100 and 320 seconds with a shallow minimum around $T=290$ seconds. For the predominantly oceanic paths the group velocities are higher than those for the other paths.

\section{ACKNOWLEDGMENTS}

The work was supported by Grant No. AF-AFOSR-25-63 of the Air Force Office of Scientific Research as part of the Advanced Research Projects Agency Project vElA-UnIform.

The time series analysis and group velocity computer programs that were used in the analysis of the data were written by Mr. Shelton S. Alexander. Acknowledgment is also due to Dr. James Brune for clarifying certain aspects of his method. Mr. Laszlo Lenches is credited for technical aid in the preparation of this manuseript.

\section{REFERENCES}

Aki, K., and F. Press

1961. "Upper Mantle Structure Under Oceans and Continents From Rayleigh Waves," Geophys. J., 5: 292.

Båth, M., and A. L. Arroyo

1962. "Attenuation and Dispersion of G Waves," J. Geophys. Res., 67: 1933.

Ben-Menahem, A.

1961. "Radiation of Seismic Surface Waves from Finite Moving Sources," Bull. Seism. Soc. Am., 51: 401.

Ben-Menahem, A., and M. N. Toksöz

1962. "Souree-Mechanism from Spectra of Long-Period Seismic Surface Waves. I. The Mongolian Earthquake of December 4, 1957," J. Geophys. Res., 67: 1943.

Bolt, B., and A. Marussi

1962. "Eigenvibrations of the Earth Observed at Trieste," Geophys. J., 6: 299.

Brune, J. N., H. Benioff, and M. Ewing

1961. 'Long-Period Surface Waves from the Chilean Earthquake of May 22, 1960, Recorded on Linear Strain Seismographs," J. Geophys. Res., 66: 2895.

Brune, J. N., M. Ewing, and J. Kuo

1961. "Group and Phase Velocities for Rayleigh Waves of Period Greater Than 380 Seconds," Science, $133: 3455$. 
Brune, J. N., J. E. Nafe, and L. E. Alsop

1961. "The Polar Phase Shift of Surface Waves On a Sphere," Bull. Seism. Soc. Am., 51 : 247.

Brune, J. N., J. E. Nafe, and J. Oliver

1960. "A Simplified Method for the Analysis and Synthesis of Dispersed Wave Trains," J. Geophys. Res., 65: 287.

Dorman, J., M. Ewing, and J. Oliver

1960. "Study of Shear Velocity Distribution in the Upper Mantle by Mantle Rayleigh Waves," Bull. Seism. Soc. Am., 50:87.

Ewing, M., and F. Press

1954. "An Investigation of Mantle Rayleigh Waves," Bull. Seism. Soc. Am., 44: 127.

Gratsinsky, V. G.

1962. "Distortions of Seismic Pulse Spectra During Analysis," Isv. Akad. Nauk SSSR, Geophys. Ser., p. 348.

Kovach, R. L., and D. L. Anderson

1962. "Long Period Love Waves in a Heterogeneous Spherical Earth," J. Geophys. Res., $67: 5243$.

Kuo, J., J. Brune, and M. Major

1962. "Rayleigh Wave Dispersion in the Pacific Ocean for the Period Range 20 to 140 Seconds," Bull. Seism. Soc. Am., 52: 333.

Matumoto, T., and Y. Satô

1962. "Phase Velocity of Long-Period Rayleigh and Love Waves As Observed in the Chilean Earthquake of May 22, 1960," (in print).

Nafe, J. E., and J. N. Brune

1960. "Observations of Phase Velocity for Rayleigh Waves in the Period Range 100 to 400 seconds," Bull. Seism. Soc. Am., 50: 427.

Pekeris, C. L.

1948. "Theory of Propagation of Explosive Sound in Shallow Water," Geol. Soc. Amer. Mem., 27.

Pilant, W. L.

1962. (Personal Communication).

Press, F., A. Ben-Menahem, and M. N. Toksöz

1961. "Experimental Determination of Fault Length and Rupture Velocity," J. Geophys. Res., 66: 3471 .

Satô, Yasuo

1958. "Attenuation, Dispersion and the Wave Guide of the G Waves," Bull. Seism. Soc. Am., 48: 231 .

Savarensky, E. F.

1959. "On the Determination of Group and Phase Velocities from Observations," Isv. Akad. Nauk SSSR, Geophys. Ser., p. 1102.

Valle, P. E.

1949. "Sulla Misura della Velocita di Gruppo delle Onde Sismiche Superficiali," Annali di Geofisica, 2, n. 3.

SEISMOLOGICAL LABORATORY

California Institute of Technology

Pasadena, California

Drvision of the Geological Sciences

Contribution No. 1129

Manuscript received on February 6, 1963. 